\title{
$h$-Stability for Differential Systems Relative to Initial Time Difference
}

\author{
Peiguang Wang ${ }^{1}$ and Xiaowei Liu ${ }^{2}$ \\ ${ }^{1}$ College of Electronic and Information Engineering, Hebei University, Baoding 071002, China \\ ${ }^{2}$ College of Mathematics and Computer Science, Hebei University, Baoding 071002, China
}

Correspondence should be addressed to Peiguang Wang; pgwang@mail.hbu.edu.cn

Received 22 March 2013; Accepted 22 April 2013

Academic Editor: Zhenkun Huang

Copyright (C) 2013 P. Wang and X. Liu. This is an open access article distributed under the Creative Commons Attribution License, which permits unrestricted use, distribution, and reproduction in any medium, provided the original work is properly cited.

This paper investigates the relationship between an unperturbed differential system and a perturbed differential system that have initial time difference. Notions of $h$-stability for differential systems with initial time difference are introduced, and stability criteria are formulated by using variation of parameter techniques.

\section{Introduction}

It is well known that, in applications, asymptotic stability is more important than stability, because the desirable feature is to know the size of the region of asymptotic stability. However, when we study the asymptotic stability, it is not easy to deal with nonexponential types of stability. Pinto [1] introduced the notion of $h$-stability with the intention of obtaining results about stability for a weakly stable system (at least, weaker than those given exponential stability and uniform Lipschitz stability) under some perturbations and developed the study of exponential stability to a variety of reasonable systems called $h$-systems. Since then, Choi and Ryu [2], Choi et al. [3], and Choi and Koo [4] investigated $h$-stability problem for the nonlinear differential systems respectively, and Choi et al. $[5,6]$ characterized the $h$ stability in variation for nonlinear difference systems via $n_{\infty}$-similarity and Lyapunov functions and obtained some relative results. For the detailed results of $h$-stability of impulsive dynamic systems on time scale and others systems can be found in [7-10].

At present, the investigation of differential systems with initial time difference has attracted a lot of attention. This is mainly because of the fact that when considering initial value problems, it is impossible not to make errors in the starting time in dealing with real world phenomena, that is, the solutions of the unperturbed differential system may start at some initial time and the solutions of the perturbed systems may start at a different initial time. When we consider such a change of initial time for each solution, we need to deal with the problem of comparing between any two solutions which start at different times. At present, there are two methods to discuss the stability problem with initial time difference: one is the differential inequalities and comparison principle, and the other is the method of variation of parameters. For the pioneering works in this area we can refer to the papers [11, 12]. After that, there are many stability results for various of differential and difference systems; see [13-20]. However, the above results were obtained by using comparison principle and differential inequalities; there are few stability criteria by using the method of variation of parameters; see [21-24].

In this paper, we attempt to extend the notion of $h$ stability to differential systems with initial time difference, namely, initial time difference $h$-stability (ITD $h S$ ) and then establish some stability criteria for such differential systems by using the method of variation of parameters. The remainder of this paper is organized in the following manner. Some preliminaries are presented in Section 2. The notions of $h$ stability for differential systems with initial time difference are given in this section. In Section 3, several stability criteria are established. Finally, an example is added to illustrate the result obtained. 


\section{Preliminaries}

Let $R^{+}=[0,+\infty)$ and $R^{n}$ denotes the $n$-dimensional Euclidean space with appropriate norm $\|\cdot\|$.

Consider the differential systems:

$$
\begin{aligned}
& x^{\prime}=f(t, x), \quad x\left(t_{0}\right)=x_{0}, \quad t \geq t_{0}, t_{0} \in R^{+}, \\
& x^{\prime}=f(t, x), \quad x\left(\tau_{0}\right)=y_{0}, \quad t \geq \tau_{0}, \quad \tau_{0} \in R^{+}
\end{aligned}
$$

and the perturbed differential system of (2):

$$
y^{\prime}=F(t, y), \quad y\left(\tau_{0}\right)=y_{0}, \quad t \geq \tau_{0}, \quad \tau_{0} \in R^{+},
$$

where $f, F \in C\left[R^{+} \times R^{n}, R^{n}\right]$ are locally Lipschitzian and $f$ has continuous partial derivatives $\partial f / \partial x$ on $R^{+} \times R^{n}$. The above assumptions imply the existence and uniqueness of solutions through $\left(t_{0}, x_{0}\right)$ and $\left(\tau_{0}, y_{0}\right)$. A special case of (3) is where $F(t, y)=f(t, y)+R(t, y), R(t, y)$ is the perturbation term. Let $\eta=\tau_{0}-t_{0}>0$. Furthermore, suppose that $x\left(t, t_{0}, x_{0}\right)$ is the given solution with respect to which we shall study stability criteria.

Let us begin by defining the following notions.

Definition 1. The solution $x\left(t, \tau_{0}, y_{0}\right)$ of the system (2) through $\left(\tau_{0}, y_{0}\right)$ is said to be initial time difference $h$-stability (ITDhS) with respect to the solution $x\left(t-\eta, t_{0}, x_{0}\right)$, where $x\left(t, t_{0}, x_{0}\right)$ is any solution of the system (1), if and only if there exist $c \geq 1$ and a positive bounded continuous function $h$ defined on $R^{+}$such that

$$
\begin{aligned}
& \left\|x\left(t, \tau_{0}, y_{0}\right)-x\left(t-\eta, t_{0}, x_{0}\right)\right\| \\
& \quad \leq c\left[\left\|y_{0}-x_{0}\right\|+\left|\tau_{0}-t_{0}\right|\right] h(t) h^{-1}\left(\tau_{0}\right)
\end{aligned}
$$

for $t \geq \tau_{0}$ and $h^{-1}(t)=1 / h(t)$.

Similarly, we can define initial time difference $h$-stability (ITDhS) with respect to the solution $y\left(t, \tau_{0}, y_{0}\right)$ of the system (3) through $\left(\tau_{0}, y_{0}\right)$.

We are now in a position to give the Alekseev's formula, which is an important tool in the subsequent discussion.

Lemma 2 (see [25]). If $x\left(t, \tau_{0}, y_{0}\right)$ is the solution of (2) and exists for $t \geq \tau_{0}$, any solution $y\left(t, \tau_{0}, y_{0}\right)$ of $(3)$, with $y\left(\tau_{0}\right)=$ $y_{0}$, satisfies the integral equation:

$$
\begin{aligned}
y\left(t, \tau_{0}, y_{0}\right)= & x\left(t, \tau_{0}, y_{0}\right) \\
& +\int_{\tau_{0}}^{t} \Phi\left(t, s, y\left(s, \tau_{0}, y_{0}\right)\right) R\left(s, y\left(s, \tau_{0}, y_{0}\right)\right) d s
\end{aligned}
$$

for $t \geq \tau_{0}$, where $\Phi\left(t, \tau_{0}, y_{0}\right)=\partial x\left(t, \tau_{0}, y_{0}\right) / \partial y_{0}$.

The following lemma will also be needed in our investigations.

Lemma 3 (see [25]). Assume that $x\left(t, t_{0}, x_{0}\right)$ is the solution of (1) through $\left(t_{0}, x_{0}\right)$, which exists for $t \geq t_{0}$, and then

$$
x\left(t, t_{0}, x_{0}\right)=\left[\int_{0}^{1} \Phi\left(t, t_{0}, s x_{0}\right) d s\right] x_{0},
$$

where $\Phi\left(t, t_{0}, x_{0}\right)=\partial x\left(t, t_{0}, x_{0}\right) / \partial x_{0}$.

\section{Stability Criteria}

We shall present, in this section, the stability criteria for differential systems with initial time difference.

Theorem 4. Let $x\left(t, \tau_{0}, y_{0}\right)$ and $x\left(t-\eta, t_{0}, x_{0}\right)$ be the solutions of (2) and (1) through $\left(\tau_{0}, y_{0}\right)$ and $\left(t_{0}, x_{0}\right)$, respectively, $t \geq \tau_{0}$. Assume that

(i) $v\left(t, \tau_{0}, v_{0}\right)=x\left(t, \tau_{0}, y_{0}\right)-x\left(t-\eta, t_{0}, x_{0}\right)$, in which $v_{0}=$ $y_{0}-x_{0}$

(ii) there exists a positive bounded continuously differentiable function $h(t)$ on $R^{+}$such that

$$
\begin{aligned}
\liminf _{\delta \rightarrow 0^{-}} & \frac{\left\|v\left(t, \tau_{0}, v_{0}\right)+(\tilde{f}(t, v, \eta)) \delta\right\|-\left\|v\left(t, \tau_{0}, v_{0}\right)\right\|}{\delta} \\
\leq & h^{\prime}(t) h^{-1}(t)\left\|v\left(t, \tau_{0}, v_{0}\right)\right\|,
\end{aligned}
$$

where $\tilde{f}(t, v, \eta)=f\left(t, x\left(t-\eta, t_{0}, x_{0}\right)+v\left(t, \tau_{0}, v_{0}\right)\right)-$ $f\left(t, x\left(t-\eta, t_{0}, x_{0}\right)\right)$;

(iii) $f$ is locally Lipschitzian in time such that

$$
\begin{aligned}
& \left\|f\left(t, x\left(t-\eta, t_{0}, x_{0}\right)\right)-f\left(t-\eta, x\left(t-\eta, t_{0}, x_{0}\right)\right)\right\| \\
& \quad \leq L_{1}(t) \frac{|\eta|}{L_{2}\left(\tau_{0}\right)},
\end{aligned}
$$

where $L_{2}\left(\tau_{0}\right)=\int_{\tau_{0}}^{+\infty} h^{-1}(s) h\left(\tau_{0}\right) L_{1}(s) d s, L_{1}(s) \in$ $C\left[R^{+}, R^{+}\right]$.

Then the solution $x\left(t, \tau_{0}, y_{0}\right)$ of the system (2) is ITDhS with respect to the solution $x\left(t-\eta, t_{0}, x_{0}\right)$.

Proof. Define $z(t)=\left\|v\left(t, \tau_{0}, v_{0}\right)\right\|$ for $t \geq \tau_{0}$, and then $z\left(\tau_{0}\right)=$ $\left\|y_{0}-x_{0}\right\|$. Also,

$$
\begin{aligned}
v^{\prime}\left(t, \tau_{0}, v_{0}\right)= & x^{\prime}\left(t, \tau_{0}, y_{0}\right)-x^{\prime}\left(t-\eta, t_{0}, x_{0}\right) \\
= & f\left(t, v\left(t, \tau_{0}, v_{0}\right)+x\left(t-\eta, t_{0}, x_{0}\right)\right) \\
& -f\left(t-\eta, x\left(t-\eta, t_{0}, x_{0}\right)\right) .
\end{aligned}
$$

Using a Taylor approximation for $v\left(t, \tau_{0}, v_{0}\right)$ and the conditions (i) and (ii), we arrive at

$$
\begin{aligned}
D_{-} z(t) & \\
= & \lim _{\delta \rightarrow 0} \inf \frac{\left\|v\left(t, \tau_{0}, v_{0}\right)+v^{\prime}\left(t, \tau_{0}, v_{0}\right) \delta\right\|-\left\|v\left(t, \tau_{0}, v_{0}\right)\right\|}{\delta} \\
\leq & h^{\prime}(t) h^{-1}(t) z(t)+L_{1}(t) \frac{|\eta|}{L_{2}\left(\tau_{0}\right)} .
\end{aligned}
$$

And then, from (10), we have

$$
\begin{aligned}
z(t) \leq & h(t) h^{-1}\left(\tau_{0}\right) \\
& \times\left(z\left(\tau_{0}\right)+\frac{|\eta|}{L_{2}\left(\tau_{0}\right)} \int_{\tau_{0}}^{+\infty} h^{-1}(s) h\left(\tau_{0}\right) L_{1}(s) d s\right) .
\end{aligned}
$$


Moreover, using the condition (iii), we obtain

$$
z(t) \leq h(t) h^{-1}\left(\tau_{0}\right)\left(\left\|y_{0}-x_{0}\right\|+|\eta|\right) .
$$

Then from (12), we get

$$
\begin{aligned}
& \left\|x\left(t, \tau_{0}, y_{0}\right)-x\left(t-\eta, t_{0}, x_{0}\right)\right\| \\
& \quad \leq\left[\left\|y_{0}-x_{0}\right\|+\left|\tau_{0}-t_{0}\right|\right] h(t) h^{-1}\left(\tau_{0}\right) .
\end{aligned}
$$

So by Definition 1 with $c=1$, the solution $x\left(t, \tau_{0}, y_{0}\right)$ of (2) is ITDhS with respect to the solution $x\left(t-\eta, t_{0}, x_{0}\right)$. This completes the proof.

Remark 5. Set $h(t)=e^{-\beta_{0} t}$, and then we can obtain Theorem 3.4 in [8].

Theorem 6. Let $y\left(t, \tau_{0}, y_{0}\right)$ be the solution of (3) through $\left(\tau_{0}, y_{0}\right)$. Assume that

(i) the solution $x\left(t, \tau_{0}, y_{0}\right)$ of (2) is ITDhS with respect to the solution $x\left(t-\eta, t_{0}, x_{0}\right)$ for $t \geq \tau_{0}$, where $x\left(t, t_{0}, x_{0}\right)$ is any solution of (1);

(ii) there exist $c \geq 1, \alpha>0$ and a positive bounded continuous function $h$ defined on $R^{+}$such that

$$
\begin{gathered}
\|\Phi(t, s, y(s))\| \leq c h(t) h^{-1}(s), \\
\|R(s, y(s))\| \leq r(s)\|y(s)\|,
\end{gathered}
$$

provided that $y\left(s, \tau_{0}, y_{0}\right) \leq \alpha, r(s) \in C\left(R^{+}, R^{+}\right)$and $\int_{\tau_{0}}^{+\infty} r(s) d s<+\infty$.

Then the solution $y\left(t, \tau_{0}, y_{0}\right)$ of (3) is ITDhS with respect to the solution $x\left(t-\eta, t_{0}, x_{0}\right)$.

Proof. Define $v\left(t, \tau_{0}, v_{0}\right)=x\left(t, \tau_{0}, y_{0}\right)-x\left(t-\eta, t_{0}, x_{0}\right)$ and $z(t)=\left\|v\left(t, \tau_{0}, v_{0}\right)\right\|$, and then $z\left(\tau_{0}\right)=\left\|y_{0}-x_{0}\right\|$. The condition (i) yields

$$
\begin{aligned}
& \left\|x\left(t, \tau_{0}, y_{0}\right)-x\left(t-\eta, t_{0}, x_{0}\right)\right\| \\
& \quad \leq c\left[\left\|y_{0}-x_{0}\right\|+\left|\tau_{0}-t_{0}\right|\right] h(t) h^{-1}\left(\tau_{0}\right) .
\end{aligned}
$$

By Lemma 2, it follows that

$$
\begin{aligned}
y\left(t, \tau_{0}, y_{0}\right)-x\left(t-\eta, t_{0}, x_{0}\right) \\
\quad=v\left(t, \tau_{0}, v_{0}\right)+\int_{\tau_{0}}^{t} \Phi(t, s, y(s)) R(s, y(s)) d s .
\end{aligned}
$$

Now taking the norms of both sides and using the triangle inequality, we have

$$
\begin{aligned}
& \left\|y\left(t, \tau_{0}, y_{0}\right)-x\left(t-\eta, t_{0}, x_{0}\right)\right\| \\
& \quad \leq z(t)+\int_{\tau_{0}}^{t}\|\Phi(t, s, y(s))\|\|R(s, y(s))\| d s .
\end{aligned}
$$

From (15), we obtain

$$
\begin{aligned}
& \left\|y\left(t, \tau_{0}, y_{0}\right)-x\left(t-\eta, t_{0}, x_{0}\right)\right\| \\
& \leq c\left[\left\|y_{0}-x_{0}\right\|+\left|\tau_{0}-t_{0}\right|\right] h(t) h^{-1}\left(\tau_{0}\right) \\
& \quad+\int_{\tau_{0}}^{t}\|\Phi(t, s, y(s))\|\|R(s, y(s))\| d s .
\end{aligned}
$$

Setting $M^{*}(t)=\left\|y\left(t, \tau_{0}, y_{0}\right)-x\left(t-\eta, t_{0}, x_{0}\right)\right\|$ and using the triangle inequality, we have

$$
\begin{aligned}
M^{*}(t) \leq & c\left[\left\|y_{0}-x_{0}\right\|+\left|\tau_{0}-t_{0}\right|\right] h(t) h^{-1}\left(\tau_{0}\right) \\
& +\int_{\tau_{0}}^{t} \operatorname{ch}(t) h^{-1}(s) r(s) M^{*}(s) d s \\
& +\int_{\tau_{0}}^{t} \operatorname{ch}(t) h^{-1}(s) r(s)\left\|x\left(s-\eta, t_{0}, x_{0}\right)\right\| d s .
\end{aligned}
$$

By using Lemma 3 and the condition (ii), we obtain

$$
\left\|x\left(t-\eta, t_{0}, x_{0}\right)\right\| \leq \alpha c h(t) h^{-1}\left(\tau_{0}\right), \quad \text { for }\left\|x_{0}\right\| \leq \alpha .
$$

Hence,

$$
\begin{aligned}
M^{*}(t) \leq & c\left\{\left\|y_{0}-x_{0}\right\|+\left|\tau_{0}-t_{0}\right|\right\} h(t) h^{-1}\left(\tau_{0}\right) \\
& +\int_{\tau_{0}}^{t} c h(t) h^{-1}(s) r(s) M^{*}(s) d s \\
& +c^{2} \alpha h(t) h^{-1}\left(\tau_{0}\right) \int_{\tau_{0}}^{t} r(s) d s .
\end{aligned}
$$

Then we have

$$
\begin{aligned}
N^{*}(t) \leq & c\left\{\left\|y_{0}-x_{0}\right\|+\left|\tau_{0}-t_{0}\right|\right\} \\
& +\int_{\tau_{0}}^{t} r^{*}(s) N^{*}(s) d s+c^{2} \alpha N_{1}\left(\tau_{0}\right),
\end{aligned}
$$

where $r^{*}(t)=c r(t), N^{*}(t)=h^{-1}(t) h\left(\tau_{0}\right) M^{*}(t)$, and $\int_{\tau_{0}}^{+\infty} r(s) d s=N_{1}\left(\tau_{0}\right)$.

By Gronwall's inequality, one gets

$$
\begin{aligned}
M^{*}(t) \leq & \left\{c\left[\left\|y_{0}-x_{0}\right\|+\left|\tau_{0}-t_{0}\right|\right]+c^{2} \alpha N_{1}\left(\tau_{0}\right)\right\} \\
& \times h(t) h^{-1}\left(\tau_{0}\right) e^{c N_{1}\left(\tau_{0}\right)} .
\end{aligned}
$$

Moreover, set

$$
\begin{aligned}
& c_{1}\left\{\left\|y_{0}-x_{0}\right\|+\left|\tau_{0}-t_{0}\right|\right\} \\
& \quad=\left\{c\left[\left\|y_{0}-x_{0}\right\|+\left|\tau_{0}-t_{0}\right|\right]+c^{2} \alpha N_{1}\left(\tau_{0}\right)\right\} e^{c N_{1}\left(\tau_{0}\right)}
\end{aligned}
$$

and $c_{1} \geq 1$, we get

$$
\begin{aligned}
& \left\|y\left(t, \tau_{0}, y_{0}\right)-x\left(t-\eta, t_{0}, x_{0}\right)\right\| \\
& \quad \leq c_{1}\left\{\left\|y_{0}-x_{0}\right\|+\left|\tau_{0}-t_{0}\right|\right\} h(t) h^{-1}\left(\tau_{0}\right) .
\end{aligned}
$$

From Definition 1, it follows that the solution of (3) is ITDhS with respect to the solution $x\left(t-\eta, t_{0}, x_{0}\right)$. This completes the proof. 


\section{Example}

Now, we shall illustrate Theorem 6 by a simple example. Consider the differential systems

$$
\begin{aligned}
& x^{\prime}=-x, \quad x\left(t_{0}\right)=x_{0}, \quad t \geq t_{0}, \quad t_{0} \in R^{+}, \\
& x^{\prime}=-x, \quad x\left(\tau_{0}\right)=y_{0}, \quad t \geq \tau_{0}, \quad \tau_{0} \in R^{+},
\end{aligned}
$$

and the perturbed differential system of (27):

$$
y^{\prime}=-y+\frac{1}{t^{2}} y, \quad y\left(\tau_{0}\right)=y_{0}, \quad t \geq \tau_{0}, \tau_{0} \in R^{+} .
$$

Define $z(t)=x\left(t, \tau_{0}, y_{0}\right)-x\left(t-\eta, t_{0}, x_{0}\right)$; by direct calculation, we have the solution of (27) given by $x\left(t, \tau_{0}, y_{0}\right)=$ $y_{0} e^{-t+\tau_{0}}$, which exists for all $t \geq \tau_{0}$, and $\Phi\left(t, \tau_{0}, y_{0}\right)=$ $\partial x\left(t, \tau_{0}, y_{0}\right) / \partial y_{0}=e^{-t+\tau_{0}}, \Phi\left(\tau_{0}, \tau_{0}, y_{0}\right)=I .\|z(t)\| \leq\left(\| y_{0}-\right.$ $\left.x_{0} \|+\left|\tau_{0}-t_{0}\right|\right) e^{-t+\tau_{0}}$, and then the solution of system (27) is ITDhS with respect to $x\left(t-\eta, \tau_{0}, x_{0}\right)$.

Now, let us begin to consider the perturbation term $F(t, y)=\left(1 / t^{2}\right) y$ of $(28)$, and we have $\left\|\left(1 / t^{2}\right) y\right\| \leq\left(1 / t^{2}\right)\|y\|$, where $\int_{\tau_{0}}^{+\infty}\left(1 / t^{2}\right) d t<+\infty$. Then by Theorem 6 , we can conclude that the solution $y\left(t, \tau_{0}, y_{0}\right)$ of (28) is ITDhS with respect to the solution $x\left(t-\eta, t_{0}, x_{0}\right)$.

\section{Acknowledgments}

This paper is supported by the National Natural Science Foundation of China (11271106) and the Natural Science Foundation of Hebei Province of China (A2013201232).

\section{References}

[1] M. Pinto, "Perturbations of asymptotically stable differential systems," Analysis, vol. 4, no. 1-2, pp. 161-175, 1984.

[2] S. K. Choi and H. S. Ryu, " $h$-stability in differential systems," Bulletin of the Institute of Mathematics, vol. 21, no. 3, pp. 245262, 1993.

[3] S. K. Choi, N. J. Koo, and H. S. Ryu, " $h$-stability of differential systems via $t_{\infty}$-similarity," Bulletin of the Korean Mathematical Society, vol. 34, no. 3, pp. 371-383, 1997.

[4] S. K. Choi and N. J. Koo, " $h$-stability for nonlinear perturbed systems," Annals of Differential Equations, vol. 11, no. 1, pp. 1-9, 1995.

[5] S. K. Choi and N. J. Koo, "Variationally stable difference systems by $n_{\infty}$-similarity," Journal of Mathematical Analysis and Applications, vol. 249, no. 2, pp. 553-568, 2000.

[6] S. K. Choi, N. J. Koo, and Y. H. Goo, "Variationally stable difference systems," Journal of Mathematical Analysis and Applications, vol. 256, no. 2, pp. 587-605, 2001.

[7] S. K. Choi, Y. H. Goo, and N. Koo, " $h$-stability of dynamic equations on time scales with nonregressivity," Abstract and Applied Analysis, vol. 2008, Article ID 632473, 13 pages, 2008.

[8] D. Kong and L. Q. Zhang, "h-stability of impulsive dynamic systems on time scales," Science Technology and Engineering, vol. 11, no. 32, pp. 7870-7872, 2011.

[9] P. G. Wang, S. J. Li, and Z. R. Zhan, " $h$-stability of differential systems," Mathematics in Practice and Theory, vol. 38, no. 10, pp. 187-190, 2008.
[10] Z. M. Wu and L. L. Yin, " $h$-stability for a class of perturbed difference systems," Journal of Mathematics and System Science, vol. 32, no. 9, pp. 1138-1144, 2012.

[11] V. Lakshmikantham and A. S. Vatsala, "Differential inequalities with initial time difference and applications," Journal of Inequalities and Applications, vol. 3, no. 3, pp. 233-244, 1999.

[12] V. Lakshmikantham, S. Leela, and J. V. Devi, "Another approach to the theory of differential inequalities relative to changes in the initial times," Journal of Inequalities and Applications, vol. 4, no. 2, pp. 163-174, 1999.

[13] T. Jankowski, "Systems of differential inequalities with initial time difference," Ukrainian Mathematical Journal, vol. 56, no. 1, pp. 139-145, 2004.

[14] T. Jankowski, "Integro-differential inequalities with initial time difference and applications," Acta Mathematica Hungarica, vol. 100, no. 4, pp. 329-342, 2003.

[15] C. Yakar, "Boundedness criteria with initial time difference in terms of two measures," Dynamics of Continuous, Discrete \& Impulsive Systems A, vol. 14, no. Advances in Dynamical Systems, suppl. S2, pp. 270-274, 2007.

[16] C. Yakar and M. D. Shaw, "Practical stability in terms of two measures with initial time difference," Nonlinear Analysis: Theory, Methods and Applications, vol. 71, no. 12, pp. 781-785, 2009.

[17] C. Yakar, "Fractional differential equations in terms of comparison results and Lyapunov stability with initial time difference," Abstract and Applied Analysis, vol. 2010, Article ID 762857, 16 pages, 2010.

[18] W. Chen, Z. Han, S. Sun, and T. Li, "Practical $\varphi_{0}$-stability for impulsive dynamic systems with time scales and initial time difference," Journal of Applied Mathematics \& Informatics, vol. 29, no. 3-4, pp. 891-900, 2011.

[19] J. Y. Bao, P. G. Wang, and C. X. Gao, "Stability criteria for differential equations with initial time difference," Acta Mathematicae Applicatae Sinica, vol. 35, no. 4, pp. 608-616, 2012.

[20] A. Li, E. Feng, and S. Li, "Stability and boundedness criteria for nonlinear differential systems relative to initial time difference and applications," Nonlinear Analysis, vol. 10, no. 2, pp. 10731080, 2009.

[21] M. D. Shaw and C. Yakar, "Generalized variation of parameters with initial time difference and a comparison result in term Lyapunov-like functions," International Journal of Non-Linear Differential Equations-Theory Methods and Applications, vol. 5, pp. 86-108, 1999.

[22] M. D. Shaw and C. Yakar, "Stability criteria and slowly growing motions with initial time difference," Problems of Nonlinear Analysis in Engineering Systems, vol. 1, pp. 50-66, 2000.

[23] C. Yarak and M. D. Shaw, "Initial time difference stability in terms of two measures and a variational comparison result," Dynamics of Continuous, Discrete \& Impulsive Systems A, vol. 15, no. 3, pp. 417-425, 2008.

[24] C. Yakar and S. G. Deo, "Variation of parameters formulae with initial time difference for linear integrodifferential equations," Applicable Analysis, vol. 85, no. 4, pp. 333-343, 2006.

[25] V. Lakshmikantham and S. G. Deo, Method of Variation of Parameters for Dynamic Systems, vol. 1, Gordon and Breach Science, London, UK, 1998. 


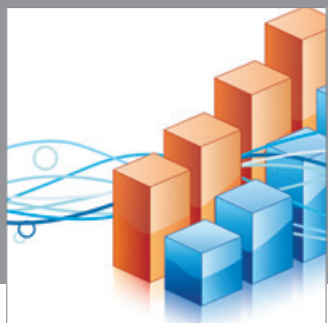

Advances in

Operations Research

mansans

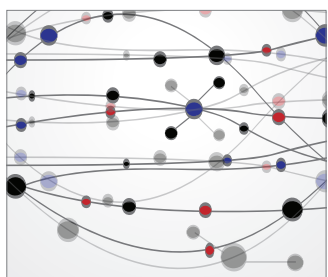

The Scientific World Journal
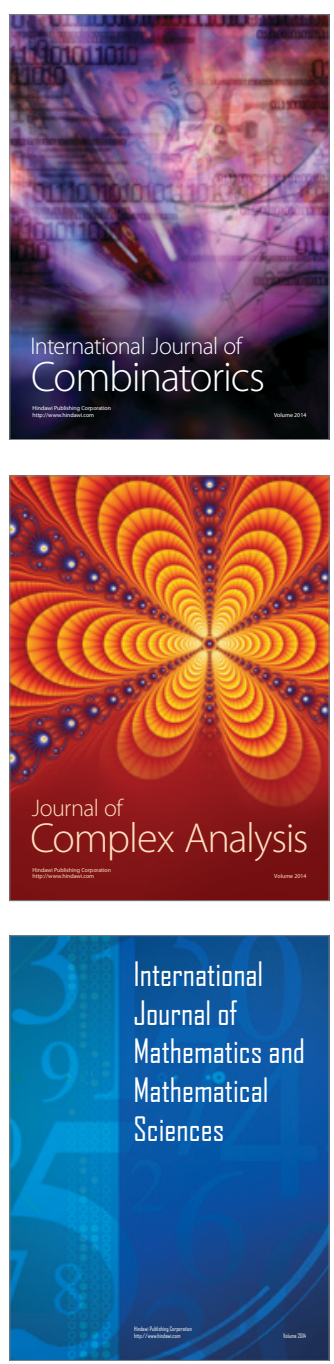
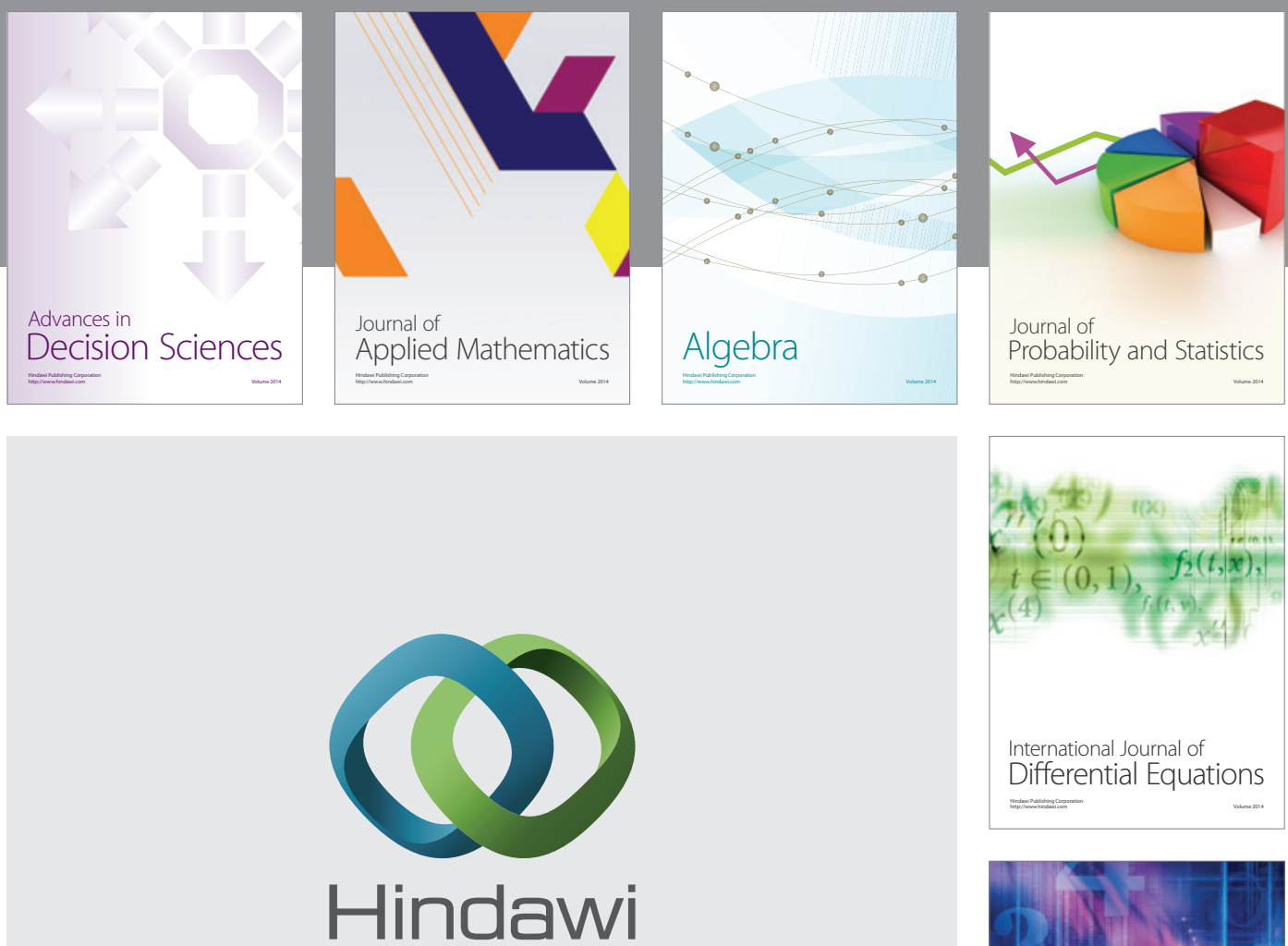

Submit your manuscripts at http://www.hindawi.com
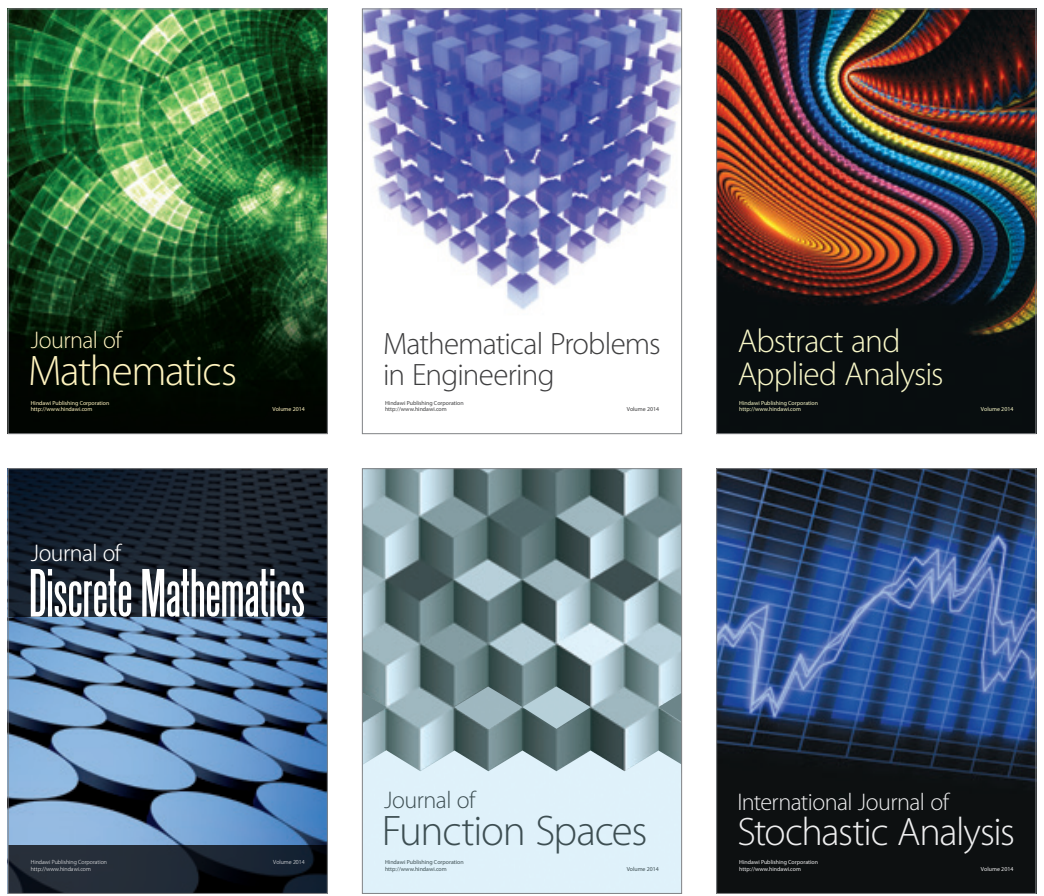

Journal of

Function Spaces

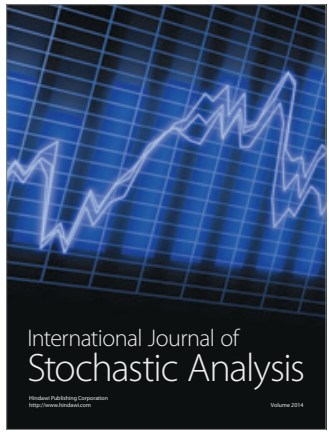

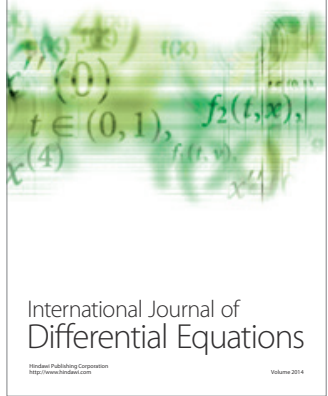
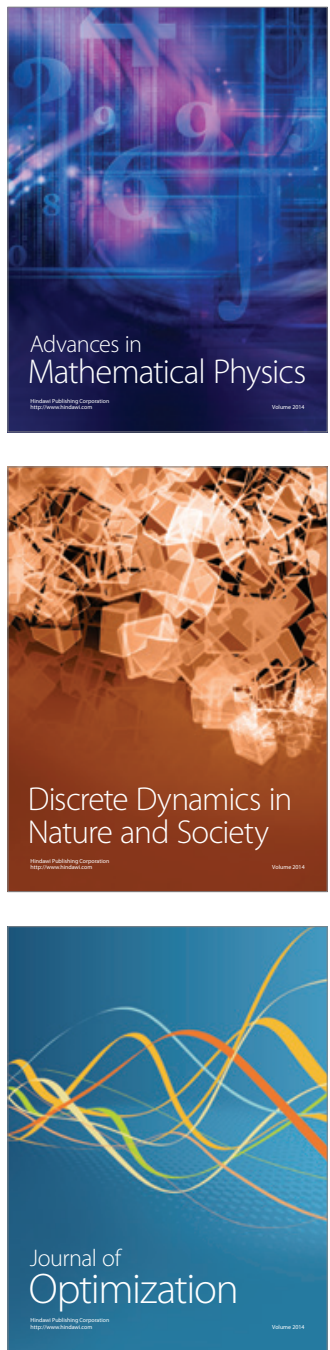